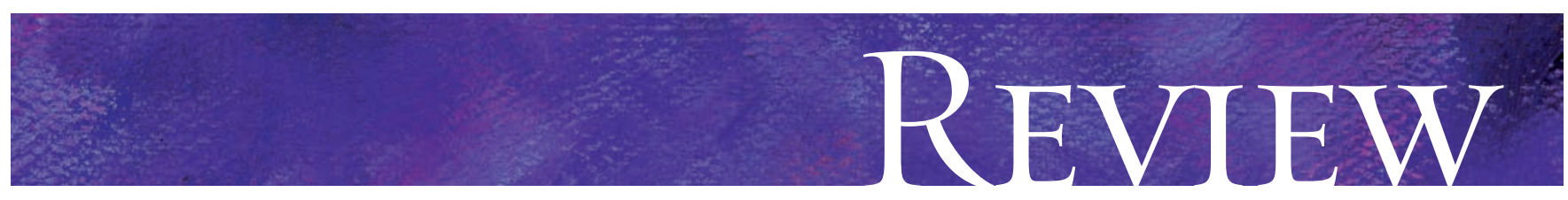

\title{
Natriuretic peptides in the diagnosis and management of heart failure
}

\author{
G. Michael Felker, John W. Petersen, Daniel B. Mark
}

\section{ABSTRACT}

The natriuretic peptides are a family of related hormones that play a crucial role in cardiovascular homeostasis. They have recently emerged as potentially important clinical markers in heart failure. Recent data have suggested an important role for these markers in establishing the diagnosis of heart failure in patients with unexplained dyspnea in both acute care and ambulatory settings. Other clinical uses of the natriuretic peptides, such as screening for asymptomatic ventricular dysfunction, establishing prognosis or guiding titration of drug therapy, are under investigation but have not yet sufficiently been validated for widespread clinical use.

CMAJ 2006;175(6):6II-7

I dentification of circulating biomarkers that may provide new windows into the pathophysiology and management of cardiovascular diseases is a major theme of contemporary research. Among the many promising candidates, 3 have reached a level of maturity deemed sufficient for clinical use: the troponins, C-reactive protein (CRP) and the natriuretic peptides. Of these, only the troponins have been fully accepted into routine clinical practice. ${ }^{1}$ CRP has provided new insights into the pathophysiology and prognosis of atherosclerotic disease, but its implications for clinical management remain controversial. ${ }^{2}$ Over the past several decades, the biological roles of the natriuretic peptides have been defined and their potential clinical uses explored in a number of different cardiovascular disorders. In this narrative review, we will summarize the evidence on the use of natriuretic peptide testing in patients with known or suspected heart failure.

\section{Historical perspective}

The path that connects the discovery of the natriuretic peptides with their current clinical roles begins over 50 years ago, when electron microscopy studies identified secretory granules in atrial muscle cells. In I98I, de Bold and colleagues from Oto tawa found that injection of atrial muscle cell extracts into rats produced a marked increase in sodium and water excretion and a drop in blood pressure. ${ }^{3}$ This "atrial natriuretic factor" was the first demonstration of an endocrine function for the heart. The structure of the responsible peptide hormone - atrial (now termed A-type) natriuretic peptide or ANP — was reported in 1983 by de Bold's group and in 1984 by Kangawa and
Matsuo in Japan. Subsequent studies identified 2 more related peptides - brain (now termed B-type) natriuretic peptide or $\mathrm{BNP}$, and C-type natriuretic peptide or CNP (which appears to act primarily in the peripheral vasculature and will not be discussed further in this review). When research laboratory assays became available for ANP and BNP in the I9gos, investigators were able to demonstrate that the levels of these hormones varied according to the presence and severity of heart failure. Most of the evidence supporting the clinical use of natriuretic peptide testing in heart failure has been published since 2000.

\section{Physiology of natriuretic peptides}

BNP and ANP are synthesized in myocytes as larger molecules (e.g., proBNP) that are subsequently cleaved to yield the active peptide hormone (e.g., BNP) and the biologically inactive Nterminal peptide fragment (e.g., NT-proBNP). Both ANP and BNP activate the same transmembrane receptor (natriuretic peptide receptor A) on target organs and as a consequence have similar physiologic effects - both hormones promote the renal excretion of sodium (natriuresis) and water (diuresis), cause vasodilation by relaxing vascular smooth muscle cells, improve diastolic relaxation (lusitropy) and decrease myocardial fibrosis. ANP and BNP do differ in their physiologic regulation, with ANP acting as the primary circulating natriuretic peptide hormone under normal conditions and BNP secretion being primarily as a result of increased myocardial wall stress. The normal circulating level of BNP is less than $20 \%$ that of ANP, but BNP is rapidly secreted by the ventricles in response to hemodynamic stress. ${ }^{4}$

ANP and BNP are removed from the circulation by 2 pathways: receptor-mediated internalization and metabolism (primarily in the kidneys), and proteolytic degradation by neutral endopeptidase in the kidneys, vascular endothelium, lungs and heart. BNP has slower clearance than ANP by both pathways. Consequently, the circulating half-life of ANP is 3-5 minutes, whereas the half-life of BNP is about 23 minutes. The inactive terminal fragment NT-proBNP has an even greater half-life than that of BNP (60-I20 minutes), which is relevant to its value as a diagnostic test.

Early studies in patients with heart failure showed that both ANP and BNP secretion from the ventricles increased in relation to the severity of ventricular dysfunction, as reflected by indices of left ventricular wall tension. ${ }^{5}$ These observations led to studies of the use of both ANP and BNP and their Nterminal fragments as diagnostic tests for heart failure. ${ }^{6}$ 
Comparisons of the diagnostic performance of ANP and BNP have generally favoured BNP. ${ }^{7}$ Thus, most of the clinical work developing natriuretic peptides as diagnostic tests has focused on BNP or NT-proBNP, and we will focus on the use of these molecules in this review.

\section{Measurement of BNP and defining normal values}

Laboratory-based assays and point-of-care assays are available for BNP and NT-proBNP using fully automated immunoassays. The most commonly used decision threshold for BNP is $100 \mathrm{pg} / \mathrm{mL}$; the corresponding values for NTproBNP are $125 \mathrm{pg} / \mathrm{mL}$ for patients less than 75 years old and $450 \mathrm{pg} / \mathrm{mL}$ for those 75 or older. Different commercial assays for BNP do not give interchangeable results, and therefore the assay being used must be noted when interpreting clinical test results as well as results from published studies. ${ }^{8}$ Available data suggest that the BNP and NT-proBNP have similar accuracy in the diagnosis of acute dyspnea. ${ }^{9}$

Levels of both molecules are elevated with aging and are higher in women than in men. ${ }^{10} \mathrm{~A}$ useful rule of thumb is that the BNP level in a normal person should be less than half their chronologic age. ${ }^{11}$ Obesity has also recently emerged as another possible confounder of natriuretic peptide measurement, with lower natriuretic peptide levels observed with progressively higher body mass index (BMI). ${ }^{12,13}$ Among 746 apparently healthy subjects in one study, however, BMI had no effect on NT-proBNP levels after adjusting for age and sex. ${ }^{14}$ In the Dallas Heart Study, both BNP and NT-proBNP levels were associated more strongly with greater lean rather than fat mass. ${ }^{15}$ Some investigators have suggested that lower levels of natriuretic peptides observed in obese patients may contribute to the association between obesity and hypertension and related disorders. ${ }^{16}$

Box 1: Potential causes of elevated B-type natriuretic peptide levels

Cardiac

- Heart failure

- Diastolic dysfunction

- Acute coronary syndromes

- Hypertension with left ventricular hypertrophy

- Valvular heart disease (aortic stenosis, mitral valve regurgitation)

- Atrial fibrillation

Noncardiac

- Acute pulmonary embolism

- Pulmonary hypertension (primary or secondary)

- Sepsis (possibly due to tissue hypoxia or secondary myocardial depression)

- Chronic obstructive pulmonary disease with cor pulmonale or respiratory failure

- Hyperthyroidism
Renal insufficiency affects the levels of both BNP and NTproBNP. In one large registry study, BNP had a modest correlation with renal function, and levels were increased in patients with a creatinine clearance of less than $60 \mathrm{~mL} \cdot \mathrm{min}^{-1} \cdot 1.73 \mathrm{~m}^{-2}$. The investigators proposed that the reference value for these patients should be $200 \mathrm{pg} / \mathrm{mL} .{ }^{17} \mathrm{~A}$ similar NT-proBNP study found a moderately strong inverse relation with renal function, and the authors recommended a reference value of $\mathrm{I} 200 \mathrm{pg} / \mathrm{mL}$ for patients with an estimated creatinine clearance below $60 \mathrm{~mL} \cdot \mathrm{min}^{-1} \cdot 1.73 \mathrm{~m}^{-2} .{ }^{18}$

In addition to the factors discussed above, BNP levels may be altered by co-existing cardiovascular diseases and by noncardiovascular diseases (Box I). In the remainder of this review, we will use BNP as a general term and specify BNP or NT-proBNP when discussing specific studies (Table $\mathrm{I}^{19}$ ).

\section{Diagnostic use of BNP testing in the evaluation of acute dyspnea}

Four major applications of BNP testing in heart failure patients have emerged over the last decade (Table 2) ${ }^{20-27} \mathrm{Be}-$ cause the diagnosis of heart failure is often challenging, the possibility that a serologic test might provide either simplification or improved accuracy has great appeal.

Methodologic challenges in interpreting the literature on the diagnostic uses of BNP derive from 3 sources. First, many investigations empirically derive a new BNP positive/negative cut point in each new dataset without then validating the performance of this cut point in an independent dataset. This practice makes comparison across studies difficult and, without validation, the reader should be skeptical that the test will be as accurate in routine clinical practice. Second, many studies are small, single-centre investigations that cannot offer robust guidance on the clinical utility of these tests. Finally, many reports on the diagnostic use of BNP testing in heart failure present the negative predictive value of the test as if it were another measure of test performance, such as sensitivity and specificity. The negative predictive value, however, is simply the post-test probability of disease following a negative test

Table 1: Characteristics of B-type natriuretic peptide (BNP) and $\mathrm{N}$-terminal BNP fragment (NT-proBNP)

\begin{tabular}{|c|c|c|}
\hline Characteristic & BNP & NT-proBNP \\
\hline Size, no. of amino acids & 32 & 76 \\
\hline Activity & Bioactive & Inactive \\
\hline $\begin{array}{l}\text { Normal plasma } \\
\text { concentration, } \mathrm{pg} / \mathrm{mL}\end{array}$ & $5-50$ & $7-160$ \\
\hline Half-life in plasma, min & $\sim 22$ & $\sim 60-120$ \\
\hline $\begin{array}{l}\text { Time to reflect meaningful } \\
\text { hemodynamic changes, } \mathrm{h}\end{array}$ & $\sim 2$ & $\sim 12$ \\
\hline $\begin{array}{l}\text { Approved cutoff to define } \\
\text { abnormal range, }{ }^{*} \mathrm{pg} / \mathrm{mL}\end{array}$ & 100 & $\begin{array}{l}125(<75 \mathrm{yr}) \\
450(\geq 75 \mathrm{yr})\end{array}$ \\
\hline
\end{tabular}

Modified, with permission, from Rademaker and Richards. ${ }^{19}$ (C) Biochemical Society. *As defined by package insert for Biosite (BNP) and Roche Diagnostics (NT-proBNP) assays. 
result. Consequently, it varies as a function of both disease prevalence (pre-test probability) and test accuracy (sensitivity and specificity), as specified in Bayes' Theorem. Reporting of the post-test probability of acute heart failure in the same population in which sensitivity and specificity were measured is of little practical use to clinicians who will often need to make decisions regarding the management of patients with different pre-test probabilities of disease. Thus, the important parameters to examine in this literature include the prevalence of disease in the tested population and the estimated accuracy parameters, which can be usefully summarized as the likelihood ratios for a positive and negative test. ${ }^{28}$

The strongest evidence for the use of BNP testing is in the evaluation of heart failure as a cause of acute dyspnea in the emergency department. Wang and colleagues recently published a meta-analysis examining the value of BNP measurement in this setting. ${ }^{29}$ Studies involving ANP or NT-proBNP alone were excluded. These investigators identified II studies published between I994 and July 2005 and judged 7 to be in the top 2 tiers of quality owing to prospective design, use of consecutive or random patients and use of 2 or more blinded raters to establish the diagnosis of heart failure. These II studies employed 5 different binary cut points to establish a "positive" BNP test result, ranging from $50 \mathrm{pg} / \mathrm{mL}$ to $250 \mathrm{pg} / \mathrm{mL}$. As expected, with lower threshold values for a positive test result, sensitivity improved while specificity declined substantially. An elevated BNP, however defined, raised the likelihood of heart failure as the correct diagnosis by about 2-4.5 times, whereas a value below $250 \mathrm{pg} / \mathrm{mL}$ decreased the likelihood of heart failure by about 90\%. In contrast, a subjective assess- ment by an emergency physician of a high clinical pre-test probability ( $\geq 80 \%$ ) increased the likelihood of heart failure by ro times, whereas a low pre-test probability $(\leq 20 \%)$ as assessed by an emergency physician reduced the post-test probability of heart failure by $35 \%$.

The largest study to evaluate the role of BNP in the diagnosis of acute dyspnea was the Breathing Not Properly (BNP) Multinational Study, a prospective multicentre registry of I586 patients. ${ }^{20}$ Results of BNP assays were not available to the treating physicians, and a final diagnosis for each patient was adjudicated by a panel of cardiologists (who were also blinded to the BNP results). The prevalence of heart failure in this population was $47 \%$. BNP levels were significantly greater (mean BNP $675 \mathrm{pg} / \mathrm{mL}$ ) among patients with a final diagnosis of heart failure than among those with left ventricular dysfunction but another cause of dyspnea (mean BNP $346 \mathrm{pg} / \mathrm{mL}$ ) or no left ventricular dysfunction or heart failure (mean BNP IIo pg/mL). A BNP cutoff of Ioo pg/mL was selected for clinical use (sensitivity $90 \%$, specificity $76 \%$ ).

The ProBNP Investigation of Dyspnea in the Emergency Department (PRIDE) study used a design similar to the BNP Study to evaluate the utility of NT-proBNP in the emergency department evaluation of 600 dyspnea patients presenting to a single Boston medical centre. ${ }^{21}$ The prevalence of acute heart failure in this cohort was $35 \%$. A decision level of less than $450 \mathrm{pg} / \mathrm{mL}$ had a sensitivity of $98 \%$ and specificity of $76 \%$ (Fig. I). As in the BNP Study, ${ }^{30}$ the use in PRIDE of the emergency physician's initial clinical assessment together with NTproBNP was superior to either factor alone and gave the best combination of sensitivity and specificity. Clinical and BNP

Table 2: Major applications of BNP testing in heart failure patients

\begin{tabular}{|c|c|c|c|}
\hline Indication; study & Marker & Clinical setting & Comment \\
\hline \multicolumn{4}{|l|}{ Diagnosis } \\
\hline Maisel et $\mathrm{al}^{20}$ & BNP & $\begin{array}{l}\text { ED patients with acute } \\
\text { dyspnea }\end{array}$ & $\begin{array}{l}\text { Level of } 100 \mathrm{pg} / \mathrm{mL} \text { identified as optimal cutoff for diagnosis } \\
\text { of heart failure }\end{array}$ \\
\hline Januzzi et $\mathrm{al}^{21}$ & NT-proBNP & $\begin{array}{l}\text { ED patients with acute } \\
\text { dyspnea }\end{array}$ & $\begin{array}{l}\text { Level }>450 \mathrm{pg} / \mathrm{mL} \text { in patients aged }<50 \mathrm{yr} \text { and }>900 \mathrm{pg} / \mathrm{mL} \\
\text { in patients } \geq 50 \mathrm{yr} \text { identified as optimal cutoff for diagnosis; } \\
\text { subsequently validated in independent dataset }{ }^{22}\end{array}$ \\
\hline Cowie et $\mathrm{al}^{23}$ & BNP & Primary care clinic & $\begin{array}{l}\text { Level of } 76 \mathrm{pg} / \mathrm{mL} \text { identified as optimal cutoff for diagnosis } \\
\text { of heart failure }\end{array}$ \\
\hline \multicolumn{4}{|l|}{ Screening } \\
\hline Vasan et $\mathrm{al}^{24}$ & BNP & $\begin{array}{l}\text { Observational cohort } \\
\text { study }\end{array}$ & $\begin{array}{l}\text { Area under ROC curve }<0.75 \text { for detecting asymptomatic left } \\
\text { ventricular dysfunction, which suggests poor performance as } \\
\text { screening test }\end{array}$ \\
\hline Redfield et $\mathrm{al}^{25}$ & BNP & $\begin{array}{l}\text { Observational cohort } \\
\text { study }\end{array}$ & $\begin{array}{l}\text { Area under ROC curve }<0.75 \text { for identifying subclinical } \\
\text { diastolic dysfunction, which suggests poor performance as a } \\
\text { screening test }\end{array}$ \\
\hline \multicolumn{4}{|l|}{ Prognosis } \\
\hline Anand et $\mathrm{al}^{26}$ & BNP & $\begin{array}{l}\text { Clinical trial of } \\
\text { valsartan }\end{array}$ & $\begin{array}{l}\text { Level }>97 \mathrm{pg} / \mathrm{mL} \text { associated with doubling of long-term } \\
\text { morbidity and mortality (relative risk } 2.1 \text { ) }\end{array}$ \\
\hline \multicolumn{4}{|l|}{ Guiding therapy } \\
\hline Troughton et $\mathrm{al}^{27}$ & NT-proBNP & $\begin{array}{l}\text { Randomized clinical } \\
\text { trial }\end{array}$ & $\begin{array}{l}\text { Therapy guided by NT-proBNP levels associated with } \\
\text { significant decrease in composite of heart failure, hospital } \\
\text { admission or death }\end{array}$ \\
\hline
\end{tabular}

Note: $\mathrm{BNP}=\mathrm{B}$-type natriuretic peptide, $\mathrm{ED}=$ emergency department, NT-proBNP $=\mathrm{N}$-terminal BNP fragment, ROC $=$ receiver operating characteristic . 
data were formed into an 8-item diagnostic heart failure score using logistic regression analysis (Table 3), and the score was then externally validated in an independent study cohort from New Zealand. ${ }^{22}$ As shown in Fig. 2, the score showed a strong linear association with the diagnosis of acute heart failure.

As with other diagnostic tests, BNP has the greatest chance to change management when it is measured in patients in whom there is the most diagnostic uncertainty. Based on simple Bayes' Theorem considerations, in patients with pretest probabilities of about $50 \%$, a likelihood ratio for a positive test (sensitivity/[1 - specificity], or the ratio of true positives to false positives) of about Io is needed to raise diagnostic certainty after testing to $90 \%$ or more (see Fig. 3 ). ${ }^{31}$ In the meta-analysis of Wang and colleagues, a high clinical index of suspicion for heart failure had a likelihood ratio of about Io, whereas a "positive" BNP had a likelihood ratio of 3 to $4 .{ }^{29}$ Of note, the likelihood ratio for either a high clinical suspicion or a BNP level of Ioo $\mathrm{pg} / \mathrm{mL}$ or greater was 3.I, which was not a significant improvement over BNP alone. In contrast, Wang and colleagues calculated a likelihood ratio for a "negative" BNP ([1 - sensitivity]/specificity, or the ratio of false negatives to true negatives)

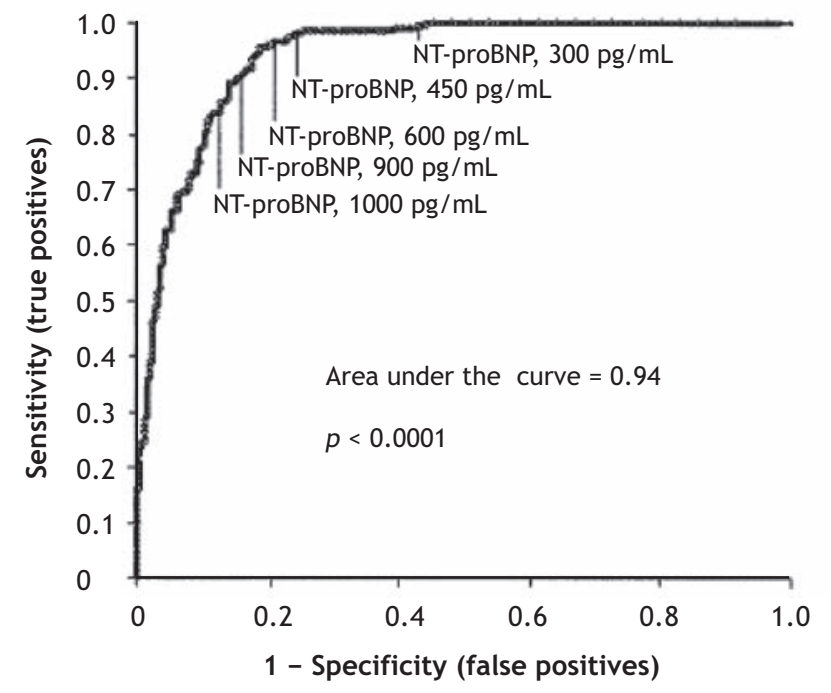

\begin{tabular}{rccccc}
\hline $\begin{array}{l}\text { Cutoff, } \\
\mathrm{pg} / \mathrm{mL}\end{array}$ & Sensitivity, \% & Specificity, \% & PPV, \% & NPV, \% & Accuracy, \% \\
\hline 300 & 99 & 68 & 62 & 99 & 79 \\
450 & 98 & 76 & 68 & 99 & 83 \\
600 & 96 & 81 & 73 & 97 & 86 \\
900 & 90 & 85 & 76 & 94 & 87 \\
1000 & 87 & 86 & 78 & 91 & 87 \\
\hline
\end{tabular}

Note: $\mathrm{PPV}=$ positive predictive value, NPV = negative predictive value.

Fig. 1: Receiver operating characteristic (ROC) curve for $\mathrm{N}$ terminal B-type natriuretic peptide fragment (NT-proBNP) in the PRIDE study involving 600 patients presenting to the emergency department with acute dyspnea. Five possible decision thresholds are shown, ranging from 300 to $1000 \mathrm{pg} / \mathrm{mL}$, with corresponding sensitivities and specificities. Reproduced, with permission, from Januzzi et al. ${ }^{21}$ Additional data provided by Januzzi. of o.II, which would move patients in whom there is diagnostic uncertainty to a post-test probability of Io\% or less.

One important but infrequently discussed issue is how low the post-test probability of heart failure needs to be for the clinician to be able to make confident management decisions. If the post-test probability of heart failure after a negative BNP test result is about 10\%, as shown in Fig. 3, then Io of every Ioo such patients who are sent home with reassurance and nonspecific therapy will, in fact, have acute heart failure. Whether this is an acceptable error rate depends on the consequences of failing to admit and treat the patient in a timely fashion, an issue that has not been adequately examined. If the clinician requires a higher level of certainty before deciding to discharge a patient from the emergency department (e.g., post-test probability $\leq 5 \%$ ), a negative BNP test result will only provide this if the pre-test probability is less than or equal to about $35 \%$ (i.e., lower than in either the BNP Multinational Study or the PRIDE Study).

Based on these considerations, the BNP and NT-proBNP are most useful in patients presenting to the emergency department with acute dyspnea with a low to intermediate pre-test probability if the test results are negative according to conventional decision levels. If the clinician's pre-test probability of heart failure as the cause of the patient's dyspnea is high, a negative BNP test result should not, by itself, be used to dismiss the diagnosis.

\section{Diagnostic uses of BNP in the nonacute setting}

\section{Heart failure}

The possibility that BNP testing might be of use in the diagnosis of heart failure in the primary care setting was first examined by Cowie and colleagues. ${ }^{23}$ They studied 122 consecutive patients who were referred by their general practitioner to a heart failure clinic in west London over a 15 -month pe-

\begin{tabular}{|c|c|}
\hline Component & Points \\
\hline $\begin{array}{l}\text { Elevated NT-proBNP level } \\
>450 \mathrm{pg} / \mathrm{mL} \text { if age }<50 \mathrm{yr} \\
>900 \mathrm{pg} / \mathrm{mL} \text { if age } \geq 50 \mathrm{yr}\end{array}$ & 4 \\
\hline $\begin{array}{l}\text { Interstitial edema on chest } \\
\text { radiograph }\end{array}$ & 2 \\
\hline Orthopnea & 2 \\
\hline Absence of fever & 2 \\
\hline Current loop diuretic use & 1 \\
\hline Age $>75 \mathrm{yr}$ & 1 \\
\hline Rales on lung examination & 1 \\
\hline Lack of cough & 1 \\
\hline Total score & $0-14$ \\
\hline
\end{tabular}


riod. The median interval between initial evaluation and referral was 4 days. The "gold standard" diagnosis of heart failure was made by a panel of 3 cardiologists using retrospective record review. In this early study, no formal quantification of pretest probability was made. For a BNP level of $76 \mathrm{pg} / \mathrm{mL}(22 \mathrm{pmol} / \mathrm{L})$ or greater, the authors calculated a sensitivity of $97 \%$ and specificity of $84 \%$. The corresponding likelihood ratios for a positive and negative test result are 6.I and 0.04 . Thus, greater diagnostic certainty is again provided for patients who, on clinical evaluation, have a low to intermediate pretest probability of heart failure together with a negative BNP test result.

In a randomized trial that enrolled 305 elderly outpatients with symptoms of dyspnea or edema of recent onset, general practitioners became more accurate in their diagnosis of heart failure with the addition of NT-proBNP results to the standard clinical assessment ( $70 \%$ correct diagnosis with BNP results v. $59 \%$ without BNP results). ${ }^{32}$ Most of the improved accuracy was due to enhanced correct elimination of the diagnosis of heart failure as the cause of symptoms.

\section{Left ventricular dysfunction}

Two groups of investigators have performed systematic reviews on the diagnostic uses of BNP measurement in heart failure. ${ }^{7,33}$ Latour-Perez and colleagues identified 25 studies of adequate quality examining the ability of BNP to identify systolic dysfunction. ${ }^{33}$ The studies were clinically heterogeneous in the types of patients studied, in the BNP cut points used and in the definition of systolic dysfunction. The summary diagnostic odds ratio showed strong evidence of statistical heterogeneity and evidence of publication bias.

A recent representative study involved a randomly selected population of Olmstead County residents over 45 years old who underwent echocardiography and BNP testing. Using the empirically derived BNP cutoff of $55 \mathrm{pg} / \mathrm{mL}$ for the identi-

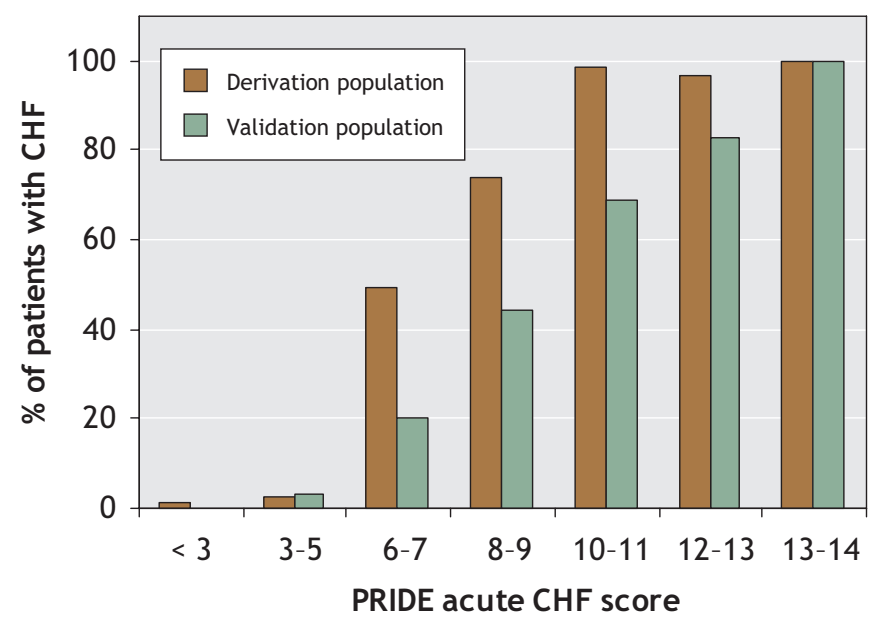

Fig. 2: Performance of acute congestive heart failure score in the diagnosis of heart failure in the derivation cohort from the PRIDE study (light bars) and the validation cohort from New Zealand (dark bars). Modified, with permission, from Baggish et al. ${ }^{22}$ fication of preclinical systolic dysfunction (ejection fraction $\leq 40 \%$, which had a prevalence of $\mathrm{r} \%$ ), the authors found that a positive BNP test result had a likelihood ratio of 3.8 , whereas a negative result had a likelihood ratio of o.I. ${ }^{25}$ In this population, using BNP measurement as an initial screen would lead to a referral for echocardiography in $24 \%$ of the patients. In $96 \%$ of these studies, the results would be negative for systolic dysfunction. Comparable results were reported in the Framingham Offspring Study. ${ }^{24}$ For detection of moderate or severe diastolic dysfunction, the situation is even less favourable. Use of an empirically derived cut point of $36 \mathrm{pg} / \mathrm{mL}$ yielded a positive likelihood ratio of 2.4 and a negative likelihood ratio of o.4. A "positive" BNP would lead to $34 \%$ of patients being referred for echocardiography, of whom $85 \%$ would have negative findings. Taken as a whole, these data suggest that the use of natriuretic peptides for screening asymptomatic populations is not likely to be cost-effective. ${ }^{34}$

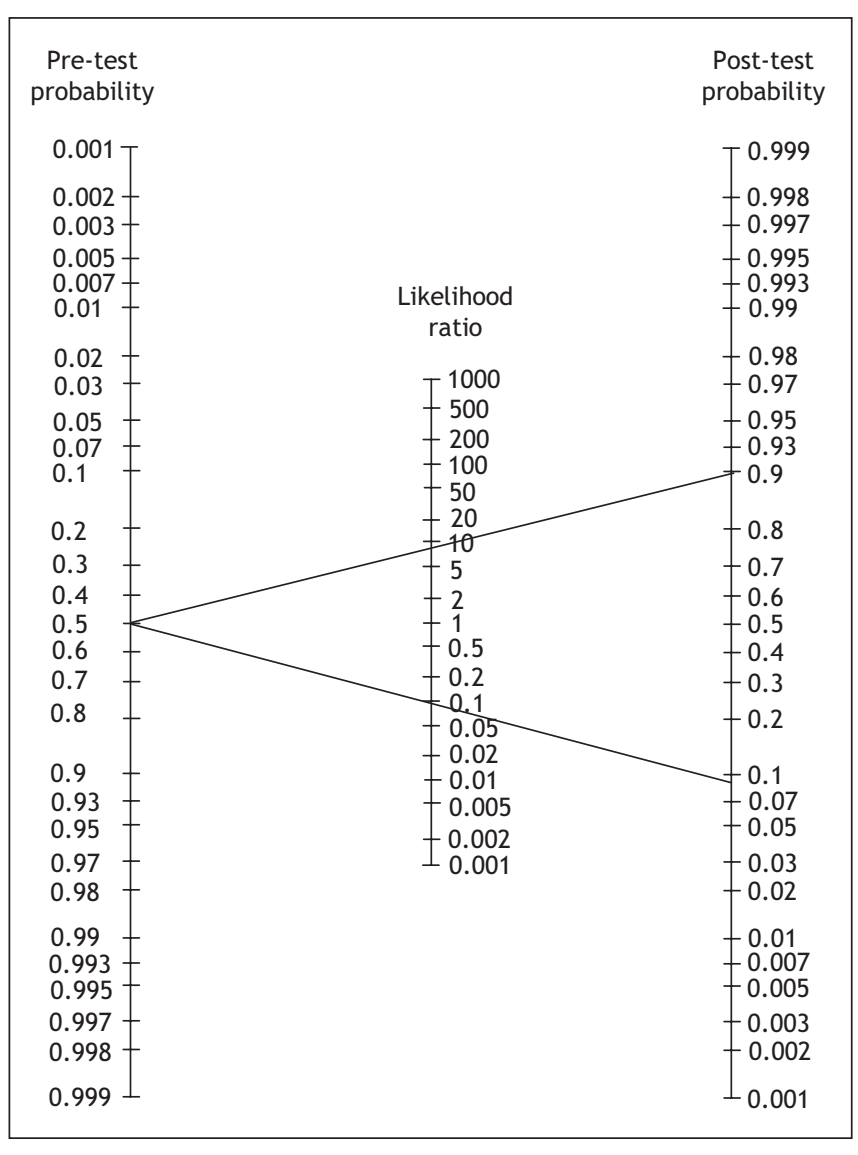

Fig. 3: Nomogram version of Bayes' Theorem. Starting with a patient in whom the diagnosis is uncertain after clinical evaluation (e.g., pretest probability of $50 \%$ ), a likelihood ratio of 10 or greater for a positive test result is required to rule in disease with reasonable certainty (i.e., post-test probability of $90 \%$ or greater), whereas a likelihood ratio of 0.10 or smaller for a negative test result is required to rule out disease with reasonable certainty (i.e., post-test probability of $10 \%$ or lower). Adapted, with permission, from Fagan TJ. Nomogram for Bayes' formula. N Engl J Med 1975;293:257. Copyright (๑ 1975 Massachusetts Medical Society. All rights reserved. 


\section{Prognostic uses of BNP in heart failure}

Doust and colleagues identified I9 studies examining the prognostic value of BNP or NT-proBNP in heart failure. ${ }^{35}$ These studies were published between 1994 and March 2004 and differed in how they analyzed BNP (as a continuous variable v. dichotomized into groups) and whether they examined survival alone or combined cardiac events (typically death or hospital admission). Pooled analysis of 4 studies that used continuous BNP to predict all-cause mortality indicated that, for each $100 \mathrm{pg} / \mathrm{mL}$ rise in BNP, the relative risk of death increased by $35 \%$. The studies using a dichotomous BNP were more variable. The largest of these, the Valsartan Heart Failure Trial (Val-HeFT) using a subset of 3618 patients, reported a doubling of mortality among patients with a BNP level greater than $97 \mathrm{pg} / \mathrm{mL} .{ }^{26}$ Although these data support the strong prognostic value of natriuretic peptide levels, it should be noted that this literature is particularly susceptible to publication bias (i.e., studies that found weak or no association between BNP and prognosis are less likely to be published).

Logeart and colleagues examined the prognostic value of serial admission and discharge BNP measurements among I05 patients surviving hospital stay for decompensated heart failure and discharged with either New York Heart Association (NYHA) class II or III disease. ${ }^{36}$ The predischarge BNP was the strongest predictor of death or readmission because of heart failure, whereas admission BNP, and clinical and echocardiography parameters did not add independent information. A BNP level of $350 \mathrm{pg} / \mathrm{mL}$ was selected as the best cutoff for clinical use. In a subsequent validation cohort of Iog patients, the use of this BNP cutoff had a sensitivity of $80 \%$ and a specificity of $88 \%$ for identifying subsequent death or hospital admission at 6 months. Similar results have recently been reported by Verdiani and coworkers. ${ }^{37}$

\section{Monitoring response to heart failure therapy with BNP}

The case for BNP-guided therapy depends on several important assumptions. The first, for which there is reasonable evidence, is that therapies that reduce adverse clinical events in heart failure also reduce BNP levels. BNP levels have improved with a variety of drug therapies known to be efficacious in heart failure, including angiotensin-convertingenzyme (ACE) inhibitors, ${ }^{38}$ angiotensin-receptor blockers, ${ }^{39}$ $\beta$-blockers ${ }^{40}$ and spironolactone. ${ }^{41}$

The second assumption, for which there is much less evidence, is that therapies that improve outcomes in heart failure do so primarily through mechanisms that are linked with changes in BNP levels. In an early study involving 20 patients with decompensated heart failure, changes in BNP levels mirrored changes in pulmonary wedge pressures.$^{42}$ However, repeated evidence in medicine that surrogate end points often do not behave as expected highlights the necessity of demonstrating in large studies the connection between changes in $\mathrm{BNP}$ and patient outcomes.

Finally, the concept of BNP-guided therapy presumes that
BNP data will direct the clinician to make changes in therapy that would not otherwise be made. For most of heart failure therapy, however, drug dosage is based on patient tolerance and the targets achieved in the pivotal clinical trials, not on response to therapy.$^{43}$ Only in the case of diuretic dose is there a major opportunity to alter management by providing additional information about the patient's response to therapy.

The initial study in this area involved 69 outpatients with heart failure who were randomly assigned to standard care or titration of therapy guided by NT-proBNP levels. ${ }^{27}$ In the active treatment arm of this pilot study, a prespecified algorithm was used to adjust diuretics and ACE inhibitor doses to achieve an NT-proBNP level of less than I69I pg/mL (200 pm/L). Guided therapy was associated with a significantly lower rate of the composite primary end point of cardiovascular death, hospital admission or symptoms of decompensated heart failure. At 6 months, NT-proBNP-guided therapy was associated with use of modestly higher doses of ACE inhibitors and furosemide.

A cautionary note comes in the form of a cross-sectional analysis involving 558 consecutive outpatients with stable chronic systolic heart failure. ${ }^{44}$ Of the 498 patients in this cohort with incompletely controlled symptoms of heart failure (NYHA class II or III), Io6 (2I\%) had a BNP level of less than I00 $\mathrm{pg} / \mathrm{mL}$. In the 60 asymptomatic patients (NYHA class I), the median BNP level was $\mathrm{I} 47 \mathrm{pg} / \mathrm{mL}$ and the highest values were over $500 \mathrm{pg} / \mathrm{mL}$. These data suggest that, in addition to BNP levels varying according to age and renal function, BNP levels in heart failure may depend on other currently undefined factors, such as the stage of the disease (early v. late) and genetic polymorphisms present in the patients. ${ }^{44} \mathrm{In}$ light of such interindividual variation in BNP levels, use of a common BNP target level to guide therapy may be inappropriate. ${ }^{43}$

Recently, Jourdain and colleagues reported the initial results of the Systolic Heart Failure Treatment Supported by BNP (STARS-BNP) trial, which randomly assigned 220 outpatients with systolic heart failure (NYHA class II or greater, and ejection fraction $<45 \%$ ) at a centre in France to either BNPguided therapy or standard care. ${ }^{45}$ Patients were followed every 3 to 4 months. During a median of 15 months of followup, $16 \%$ of the BNP-guided group and $27 \%$ of the usual-care group either died or were admitted to hospital because of heart failure $(p=0.00 \mathrm{I})$. The BNP-Assisted Treatment To Lessen Serial Cardiovascular Readmissions and Death (BATTLE-SCARRED) trial, which has targeted an enrolment of 360 patients, involves 3 arms: usual care, a clinical scoreguided therapy arm and an NT-proBNP-guided arm. ${ }^{46} \mathrm{~Pa}-$ tients are followed every 3 months for a minimum of $\mathrm{I}$ year. Results are expected in 2007.

\section{Conclusions and future directions}

The evidence is strongest that a low BNP level in a patient presenting to the emergency department with acute dyspnea thought possibly to be due to heart failure provides a high level of confidence that heart failure is not responsible for the patient's symptoms. Evidence on the value of BNP screening for left ventricular dysfunction either in patients with symptoms or in the apparently healthy population is currently less per- 
suasive. BNP adds significant prognostic information both for patients with heart failure and for asymptomatic adults, but the appropriate response to this increased risk in either population remains to be defined. Ongoing studies that will report results over the next several years should clarify the value of serial BNP testing in the titration of therapy and will likely have the biggest impact on whether such testing assumes a more central role in the care of patients with heart failure.

\section{This article has been peer reviewed.}

From the Outcomes Research Group, Duke Clinical Research Institute, and the Division of Cardiology and Department of Medicine, Duke University Medical Center, Durham, NC (all authors).

Competing interests: None declared.

Contributors: All of the authors contributed substantially to the manuscript, including drafting the article and revising it critically for important intellectual content, and approved the submitted version.

\section{REFERENCES}

I. Braunwald E, Antman EM, Beasley JW, et al. ACC/AHA 2002 guideline update for the management of patients with unstable angina and non-ST-segment elevation myocardial infarction - summary article: a report of the American College of Cardiology/American Heart Association task force on practice guidelines (Committee on the Management of Patients With Unstable Angina). J Am Coll Cardiol 2002;40:1366-74.

2. Khera A, de Lemos JA, Peshock RM, et al. Relationship between C-reactive protein and subclinical atherosclerosis: the Dallas Heart Study. Circulation 2006;113:38-43.

3. De Bold AJ, Borenstein HB, Veress AT, et al. A rapid and potent natriuretic response to intravenous injection of atrial myocardial extract in rats. Life Sci 1981;28:89-94.

4. Mukoyama M, Nakao K, Hosoda K, et al. Brain natriuretic peptide as a novel cardiac hormone in humans. Evidence for an exquisite dual natriuretic peptide system, atrial natriuretic peptide and brain natriuretic peptide. J Clin Invest I991;87:I402-I2.

5. Yoshimura M, Yasue H, Okumura K, et al. Different secretion patterns of atrial natriuretic peptide and brain natriuretic peptide in patients with congestive heart failure. Circulation I $993 ; 87: 464-9$.

6. Davis M, Espiner E, Richards G, et al. Plasma brain natriuretic peptide in assessment of acute dyspnoea. Lancet 1994;343:440-4.

7. Doust JA, Glasziou PP, Pietrzak E, et al. A systematic review of the diagnostic accuracy of natriuretic peptides for heart failure. Arch Intern Med 2004;164:1978-84.

8. Clerico A, Prontera C, Emdin M, et al. Analytical performance and diagnostic accuracy of immunometric assays for the measurement of plasma B-type natriuretic peptide (BNP) and N-terminal proBNP. Clin Chem 2005;5I:445-7.

9. Lainchbury JG, Campbell E, Frampton CM, et al. Brain natriuretic peptide and nterminal brain natriuretic peptide in the diagnosis of heart failure in patients with acute shortness of breath. J Am Coll Cardiol 2003;42:728-35.

Io. Redfield MM, Rodeheffer RJ, Jacobsen SJ, et al. Plasma brain natriuretic peptide concentration: impact of age and gender. J Am Coll Cardiol 2002;40:976-82.

II. McCollough PA. Clinical utility of blood natriuretic peptide levels. In: Business Briefing: US Cardiology 2006. London (UK): Touch Briefings; 2006. Available: www.touchbriefings.com/pdf/I6or/McCullough.pdf (accessed $2006 \mathrm{Jul} 2 \mathrm{I}$ ).

I2. Mehra MR, Uber PA, Park MH, et al. Obesity and suppressed B-type natriuretic peptide levels in heart failure. J Am Coll Cardiol 2004;43:I590-5.

I3. Krauser DG, Lloyd-Jones DM, Chae CU, et al. Effect of body mass index on natriuretic peptide levels in patients with acute congestive heart failure: a ProBNP Investigation of Dyspnea in the Emergency Department (PRIDE) substudy. Am Heart J 2005; I49:744-50.

I4. Costello-Boerrigter LC, Boerrigter G, Redfield MM, et al. Amino-terminal pro-B-type natriuretic peptide and B-type natriuretic peptide in the general community: determinants and detection of left ventricular dysfunction. J Am Coll Cardiol 2006;47:345-53.

I5. Das SR, Drazner MH, Dries DL, et al. Impact of body mass and body composition on circulating levels of natriuretic peptides: results from the Dallas Heart Study. Circulation 2005;112:2163-8.

I6. Wang TJ, Larson MG, Levy D, et al. Impact of obesity on plasma natriuretic peptide levels. Circulation 2004;109:594-6oo.

17. McCullough PA, Duc P, Omland T, et al. B-type natriuretic peptide and renal function in the diagnosis of heart failure: an analysis from the Breathing Not Properly Multinational Study. Am J Kidney Dis 2003;4I:571-9.

I8. Anwaruddin S, Lloyd-Jones DM, Baggish A, et al. Renal function, congestive heart failure, and amino-terminal pro-brain natriuretic peptide measurement: results from the ProBNP Investigation of Dyspnea in the Emergency Department (PRIDE) Study. J Am Coll Cardiol 2006;47:9I-7.

I9. Rademaker MT, Richards AM. Cardiac natriuretic peptides for cardiac health. Clin Sci (Lond) 2005;108:23-36.
20. Maisel AS, Krishnaswamy P, Nowak RM, et al. Rapid measurement of B-type natriuretic peptide in the emergency diagnosis of heart failure. N Engl J Med 2002;347: I6I-7.

2I. Januzzi JL Jr, Camargo CA, Anwaruddin S, et al. The N-terminal Pro-BNP investigation of dyspnea in the emergency department (PRIDE) study. Am J Cardiol 2005;95:948-54.

22. Baggish AL, Siebert U, Lainchbury JG, et al. A validated clinical and biochemical score for the diagnosis of acute heart failure: the ProBNP Investigation of Dyspnea in the Emergency Department (PRIDE) Acute Heart Failure Score. Am Heart ) 2006;I5I:48-54.

23. Cowie MR, Struthers AD, Wood DA, et al. Value of natriuretic peptides in assessment of patients with possible new heart failure in primary care. Lancet I997;350:1349-53.

24. Vasan RS, Benjamin EJ, Larson MG, et al. Plasma natriuretic peptides for community screening for left ventricular hypertrophy and systolic dysfunction: the Framingham heart study. JAMA 2002;288:1252-9.

25. Redfield MM, Rodeheffer RJ, Jacobsen SJ, et al. Plasma brain natriuretic peptide to detect preclinical ventricular systolic or diastolic dysfunction: a community-based study. Circulation 2004;109:3176-8I.

26. Anand IS, Fisher LD, Chiang YT, et al. Changes in brain natriuretic peptide and norepinephrine over time and mortality and morbidity in the Valsartan Heart Failure Trial (Val-HeFT). Circulation 2003;I07:1278-83.

27. Troughton RW, Frampton CM, Yandle TG, et al. Treatment of heart failure guided by plasma aminoterminal brain natriuretic peptide (N-BNP) concentrations. Lancet 2000;355:1126-30.

28. Grimes DA, Schulz KF. Refining clinical diagnosis with likelihood ratios. Lancet 2005;365:1500-5.

29. Wang CS, FitzGerald JM, Schulzer M, et al. Does this dyspneic patient in the emergency department have congestive heart failure? JAMA 2005;294:1944-56.

30. McCullough PA, Nowak RM, McCord J, et al. B-type natriuretic peptide and clinical judgment in emergency diagnosis of heart failure: analysis from Breathing Not Properly (BNP) Multinational Study. Circulation 2002;106:416-22.

31. Mark DB. Decision-making in clinical medicine. In: Harrison, TR, Braunwald E, eds. Harrison's principles of internal medicine. New York: McGraw Hill; 200I. p. 8-I4.

32. Wright SP, Doughty RN, Pearl A, et al. Plasma amino-terminal pro-brain natriuretic peptide and accuracy of heart-failure diagnosis in primary care: a randomized, controlled trial. J Am Coll Cardiol 2003;42:1793-800.

33. Latour-Perez JL, Coves-Orts FJ, Abad-Terrado C, et al. Accuracy of B-type natriuretic peptide levels in the diagnosis of left ventricular dysfunction and heart failure: a systematic review. EurJ Heart Fail 2006;8:390-9

34. Frigerio M, Oliva F, Turazza FM, et al. Prevention and management of chronic heart failure in management of asymptomatic patients. Am J Cardiol 2003;9I:4F-9F.

35. Doust JA, Pietrzak E, Dobson A, et al. How well does B-type natriuretic peptide predict death and cardiac events in patients with heart failure: systematic review. BMJ 2005;330:625

36. Logeart D, Thabut G, Jourdain P, et al. Predischarge B-type natriuretic peptide assay for identifying patients at high risk of re-admission after decompensated heart failure. J Am Coll Cardiol 2004;43:635-4I.

37. Verdiani V, Nozzoli C, Bacci F, et al. Pre-discharge B-type natriuretic peptide predicts early recurrence of decompensated heart failure in patients admitted to a general medical unit. EurJ Heart Fail 2005;7:566-71.

38. Motwani JG, McAlpine H, Kennedy N, et al. Plasma brain natriuretic peptide as an indicator for angiotensin-converting-enzyme inhibition after myocardial infarction. Lancet I993;34I:Iro9-I3.

39. Latini R, Masson S, Anand I, et al. Effects of valsartan on circulating brain natriuretic peptide and norepinephrine in symptomatic chronic heart failure: the Valsartan Heart Failure Trial (Val-HeFT). Circulation 2002;106:2454-8.

40. Richards AM, Doughty R, Nicholls MG, et al. Plasma N-terminal pro-brain natriuretic peptide and adrenomedullin: prognostic utility and prediction of benefit from carvedilol in chronic ischemic left ventricular dysfunction. AustraliaNew Zealand Heart Failure Group. J Am Coll Cardiol 200I;37:I78I-7.

4I. Tsutamoto T, Wada A, Maeda K, et al. Effect of spironolactone on plasma brain natriuretic peptide and left ventricular remodeling in patients with congestive heart failure. J Am Coll Cardiol 2001;37:1228-33.

42. Kazanegra R, Cheng V, Garcia A, et al. A rapid test for B-type natriuretic peptide correlates with falling wedge pressures in patients treated for decompensated heart failure: a pilot study. JCard Fail 2001;7:21-9.

43. Packer M. Should B-type natriuretic peptide be measured routinely to guide the diagnosis and management of chronic heart failure? Circulation 2003;108:2950-3.

44. Tang WH, Girod JP, Lee MJ, et al. Plasma B-type natriuretic peptide levels in ambulatory patients with established chronic symptomatic systolic heart failure. Circulation 2003;108:2964-6.

45. Jourdain P, Funck F, Gueffet P, et al. Benefit of BNP plasma levels for optimising therapy: the systolic heart failure treatment supported by BNP multicenter randomised trial (STARS-BNP) [abstract]. J Am Coll Cardiol 2005;45:3A.

46. Lainchbury JG, Troughton RW, Frampton CM, et al. NTproBNP-guided drug treatment for chronic heart failure: design and methods in the "BATTLESCARRED" trial. Eur J Heart Fail 2006 Jul 6; [Epub ahead of print].

Correspondence to: Dr. Daniel B. Mark, Outcomes Group, Duke Clinical Research Institute, PO Box 17969, Durham NC 27705, USA; fax 9I9668-706o; markooo4@mc.duke.edu 